\title{
A new species of Rhodambulyx Mell, 1939 (Lepidoptera: Sphingidae) from Southwest Chongqing, China
}

\author{
ZHEN-BANG XU' ${ }^{1}$, TOMÁŠ MELICHAR², JI-BAI HE ${ }^{3}$, CHAO ZHANG ${ }^{4,5}$, XIN-YU ZHANG ${ }^{4,6}$, \\ DU FENG $^{4,7}$ \& SHAO-JI HU 8,9 * \\ ${ }^{1}$ Institute of Resource Plants, Yunnan University, Kunming, 650500, China. ”"zhenbang.xu@foxmail.com; @ https://orcid.org/0000- \\ 0002-8143-3064 \\ ${ }^{2}$ Sphingidae Museum,Př́bram, 7926101, Czech Republic. "="sph.melichar@seznam.cz; ○https://orcid.org/0000-0001-8589-8531 \\ ${ }^{3}$ swild, Chengdu, 610000, China. !" hejibai@swild.cn; • \\ ${ }^{4}$ Simianshan Forest Resource Service Center, Jiangjin District, Chongqing, 402296, China \\ ${ }^{5}$ इ" mythimna@foxmail.com; 10 https://orcid.org/0000-0001-6069-1059 \\ 6”-979638735@qq.com; ‘ https://orcid.org/0000-0001-7648-7677 \\ 7”353639921@qq.com; @ ittps://orcid.org/0000-0003-1377-2950 \\ ${ }^{8}$ Yunnan Key Laboratory of International Rivers and Transboundary Eco-security, Yunnan University, Kunming, 650500, China \\ ${ }^{9}$ Institute of International Rivers and Eco-security, Yunnan University, Kunming, 650500, China. \\ ${ }^{*}$ Corresponding author."shaojihu@hotmail.com; @ ittps://orcid.org/0000-0002-1615-9601
}

\begin{abstract}
A new species of the genus Rhodambulyx Mell, 1939, Rhodambulyx xinyuae sp. nov., is described from Simianshan Nature Reserve in Southwest Chongqing, China. This species is similar to $R$. davidi Mell, 1939 and R. kitchingi Brechlin, 2015 in habitus, but can be distinguished by a different wing pattern, male genitalia structure and DNA barcode sequence. In addition, Rhodambulyx namvui Eitschberger \& Nguyen, 2017 is removed from synonymy with $R$. kitchingi and synonymized instead with $R$. davidi, although whether it would be better treated as a subspecies of $R$. davidi requires further investigation.
\end{abstract}

Key words: Rhodambulyx, DNA barcode, Vietnam, hawk moth, genital structure

摘要

本文记述了红鹰天蛾属Rhodambulyx Mell, 1939一新种——芯语红鹰天蛾Rhodambulyx xinyuae sp. nov., 其标本 采集于重庆西南部的四面山自然保护区。该种与已知的近似物种大卫红鹰天蛾 $R$. davidi Mell, 1939 和凯氏红鹰 天蛾R. kitchingi Brechlin, 2015 相似, 但本种的翅面斑纹、雄性生殖器以及DNA条形码序列与上述 2 个近似种存 在明显差异。另外, 本文将Rhodambulyx namvui 由 R. kitchingi的异名变为了 R. davidi的异名, 但将 $R$. namvui 作为 R. davidi的亚种对待是否是最佳处理方式需要进一步研究。

关键词: 红鹰天蛾; DNA条形码; 越南; 天蛾; 生殖器结构

\section{Introduction}

The genus Rhodambulyx Mell, 1939 (Lepidoptera: Sphingidae: Smerinthinae) comprises a group of brown-bodied Oriental hawk moths that are commonly found in South China, and North Indochina in spring (Figure 1). The genus was originally established for a single species, Rhodambulyx davidi Mell, 1939, described from North Fukien [Fujian, China], and which has since also been found in Hunan, Guangdong, and Guizhou. Subsequently, four more species have been described: $R$. schnitzleri Cadiou, 1990 from Chiang Mai, Thailand (also found in S. W. Yunnan; Chen \& Ou 2008 and N. Thailand); R. hainanensis Brechlin, 2001 from Wuzhi Shan, Hainan (currently endemic to the mountains of Hainan Island); R. haxairei Melichar, Řezáč \& Horecký, 2014 from Ba Na Hills, Da Nang, Viet- 
nam; and R. kitchingi Brechlin, 2015 from the Ba To Mountains, Quang Ngai, Vietnam (also known from Central Vietnam). In addition, Eitschberger and Nguyen (2017) described R. namvui from northern Vietnam but it was then later synonymized with $R$. kitchingi by Eitschberger (2018) but without stating any reasons for so doing.

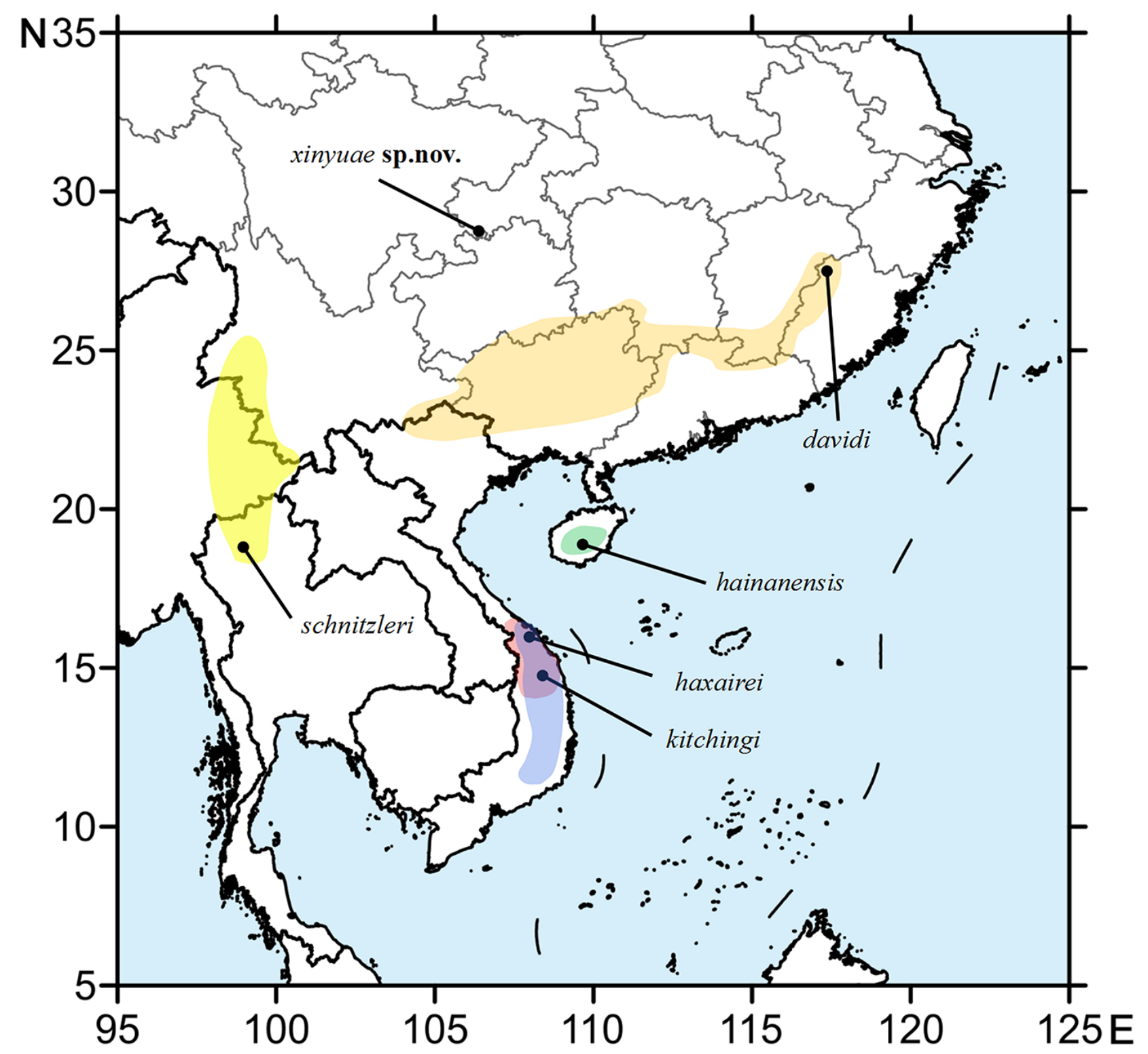

FIGURE 1. Distributions of the species of Rhodambulyx. The type localities are indicated by the black spots. In central Vietnam, the red area indicates the distribution of $R$. kitchingi, the blue area indicates the distribution of $R$. haxairei.

In 2019 and 2020, a series of brownish Rhodambulyx specimens was collected by the fourth, fifth and sixth authors from Simianshan Nature Reserve in southwest Chongqing, China. The specimens were initially identified as $R$. davidi, given its similar wing shape and occurrence in southeast China. However, after curation of these specimens, the first and third authors noticed that their wing pattern was different from that of $R$. davidi collected from Guangdong and Guangxi. Later, a series of $R$. davidi collected from its type locality were examined by the second author and he found $R$. davidi and the specimens from Chongqing could be distinguished by the presence of a paler and more clearly delimited subquadrate postmedial patch on the costa of the forewing upperside of the latter. We also considered that $R$. kitchingi from central Vietnam was a close relative and so included specimens in the morphological and genital comparisons and molecular analyses. The results suggested that the ' $R$. davidi' from Simianshan were a separate, undescribed species and we describe it below.

In addition, two samples of $R$. namvui from the type locality, including the holotype, were included in the morphological and phylogenetic analysis. The results showed that $R$. namuvi should be considered a synonym of $R$. davidi, not $R$. kitchingi (see Results section below). 


\section{Materials and methods}

\section{Abbreviations of specimen depositories}

KIZ collection of the Kunming Institute of Zoology, Chinese Academy of Science, Kunming, Yunnan, China.

SFU collection of the Southwest Forestry University, Kunming, Yunnan, China.

EMM collection of Entomologischen Museum, Marktleuten, Germany.

SMCR Sphingidae Museum, Př́ibram, Czech Republic.

ZBX Private collection of Zhen-Bang Xu, Kunming, Yunnan, China.

ZHJ Private collection of Zhuo-Heng Jiang, Hangzhou, Zhejiang, China.

Taxon sampling. Specimens of the two focal species, $R$. davidi and $R$. kitchingi were sampled for both morphological and molecular analyses, including one from northern Vietnam potentially identified as $R$. namvui. Three $R$. haxairei were also included to better understand the interspecific differences of the sympatric taxa in central Vietnam. Specimen data of all specimens used in this study are listed in Appendix 1.

For each individual used in the molecular analysis, two legs from the same side were taken for DNA extraction before the specimens were rehydrated for spreading. An individual of Rhodoprasina callantha callantha Jordan, 1929 and one of Cypoides chinensis (Rothschild \& Jordan, 1903) collected by the first author were chosen as outgroups for phylogenetic analyses, following the 'Cypa genus-group' which is a putatively monophyletic group identified by Kitching \& Cadiou (2000). In addition, seven sequences, including three individuals of $R$. davidi, two individuals of $R$. schnitzleri and two individuals of $R$. hainanensis, were downloaded from the Barcode of Life Database v.4 (BOLD) (http://www.boldsystems.org). Four unpublished sequences, including two individuals of $R$. kitchingi and two individuals of $R$. haxairei deposited in the BOLD database were also included in this study, courtesy of Mr. Jean Haxaire (Muséum national d'Histoire naturelle, Paris, France). These sequences will be published by Mr. Haxaire in due course. The collection data, GenBank accession numbers and BOLD sample IDs are listed in Table 1.

Morphological comparisons. Specimens were spread for examination, and species identification was undertaken prior to molecular analysis based on habitus. Specimens were photographed using a Canon EOS 70D digital camera (Canon, Japan), and the exposure adjusted using Adobe Photoshop CS (Adobe, USA).

The male genitalia were prepared following $\mathrm{Hu}$ et al. (2018). Forewing lengths were measured to $0.5 \mathrm{~mm}$ precision using a ruler. The whole abdomen was removed and placed into a $1.5 \mathrm{~mL}$ microcentrifuge tube, treated with $1 \mathrm{~mL} 10 \%$ sodium hydroxide solution to digest soft tissue for $1 \mathrm{~h}$ at $70{ }^{\circ} \mathrm{C}$. The treated abdomen then was neutralized with $2 \%$ acetic acid and dissected in a water-filled Petri dish under a stereoscope to remove residual tissues, scales, and hair. The genitalia were transferred to $80 \%$ glycerol for $12 \mathrm{~h}$ to render them transparent. Photographs of the genital structures were taken with a KUY NICE E3ISPM (KUY NICE, China) and automatically stacked using Helicon Focus 7 (Helicon Software, USA). Finally, all parts of the genitalia were fixed onto a glue card with watersoluble white glue and pinned with the specimen.

DNA Extraction and Amplification. The phenol-chloroform protocol was used to extract genomic DNA from two legs removed from the same side of each specimen sampled. The legs were homogenized in protease buffer containing $450 \mu \mathrm{L} \mathrm{STE} \mathrm{(10mmol/L} \mathrm{Tris-HCl,} 1 \mathrm{mmol} / \mathrm{L}$ EDTA, $100 \mathrm{mmol} / \mathrm{L} \mathrm{NaCl}, \mathrm{pH}=8.0), 25 \mu \mathrm{L}$ Proteinase K $(20 \mathrm{mg} / \mathrm{mL})$ and $75 \mu \mathrm{L} \mathrm{SDS}(10 \%)$ and incubated at $55^{\circ} \mathrm{C}$ for $12 \mathrm{~h}$ to rehydrate and lyse the tissue. The subsequent extraction protocol followed $\mathrm{Hu}$ et al. (2018) and the resultant genomic DNA preserved at $-40{ }^{\circ} \mathrm{C}$.

DNA amplification followed Xu et al. (2020). The polymerase chain reaction (PCR) was carried out in a 25 $\mu \mathrm{L}$ system using the TaKaRa Ex Taq Kit (TaKaRa Biotechnology Co., Ltd., Dalian, China). The system contained $2.5 \mu \mathrm{L} 10 \times$ PCR buffer, $2.0 \mu \mathrm{L} \mathrm{MgCl}_{2}(2.5 \mathrm{mmol} / \mathrm{L}), 2.0 \mu \mathrm{L}$ dNTP mixture $(2.5 \mathrm{mmol} / \mathrm{L}$ each $)$. The mitochondrial cox1 gene fragment (the DNA barcode) was amplified and sequenced with the primers LCO1490 (5'- GGT CAA ATC ATA AAG ATA TTG-3') and HCO2198 (5'- TAA ACT TCA GGG TGA CCA AAA AAT CA-3') (Folmer et al., 1994). The PCR thermal profile consisted of an initial denaturation at $95^{\circ} \mathrm{C}$ for $3 \mathrm{~min}, 30$ cycles of denaturation at $94{ }^{\circ} \mathrm{C}$ for $1 \mathrm{~min}$, annealing at $50{ }^{\circ} \mathrm{C}$ for $1 \mathrm{~min}$, and elongation at $72{ }^{\circ} \mathrm{C}$ for $1 \mathrm{~min}$; then a final elongation at $72{ }^{\circ} \mathrm{C}$ for 5 min. Sequencing was undertaken using an ABI Prism 3730 sequencer (Applied Biosystems, Foster City, CA, USA). 


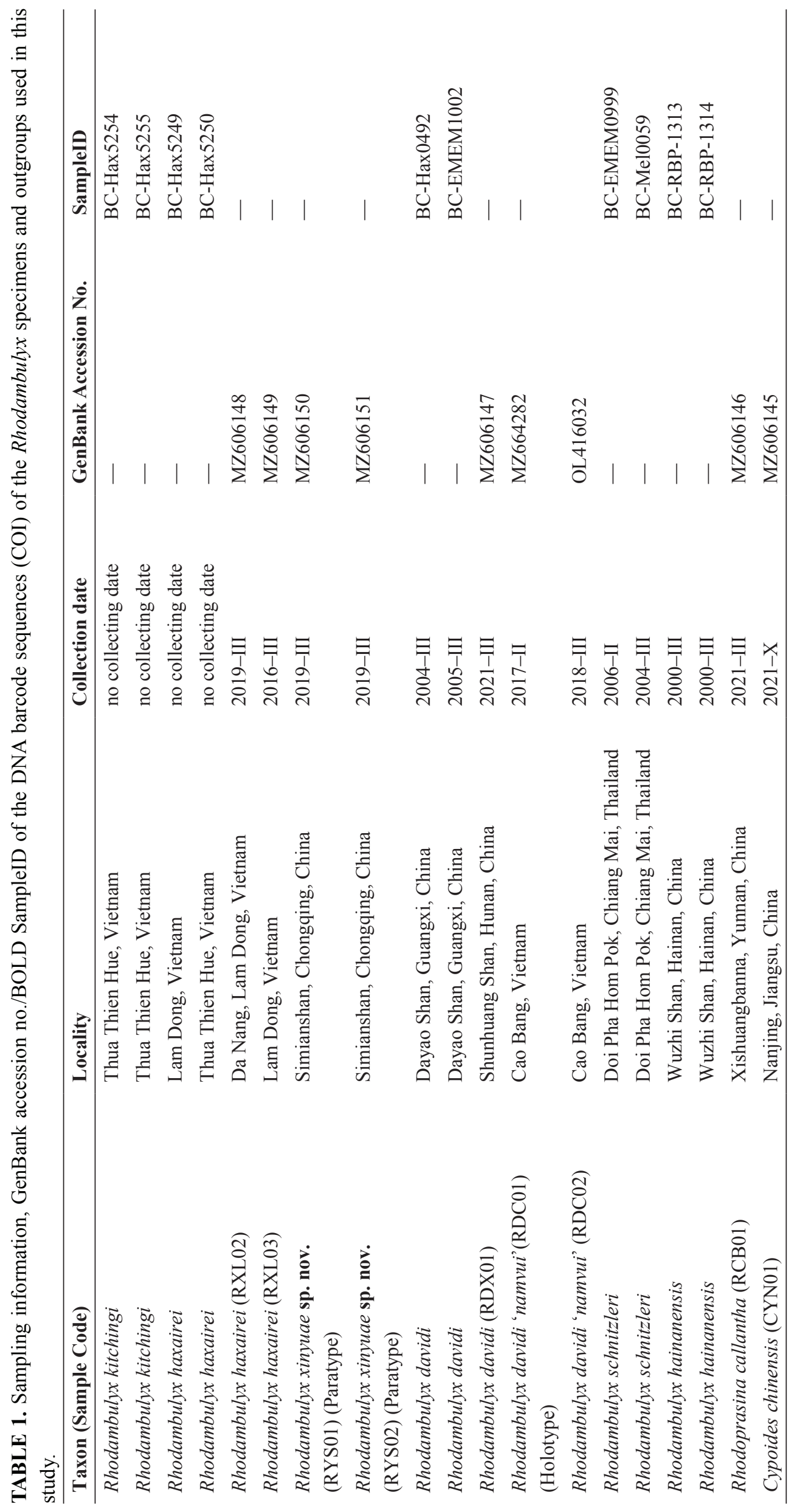


Phylogenetic Analyses and Species Delimitation. We proofread and aligned the raw sequences with ClustalW (Thompson et al. 1994) in BioEdit 7.0.9 (Hall 1999) by examining the chromatograms for polymorphic sites. MEGABLAST was used to check the identities of all sequences against genomic references and nucleotide collections in the BOLD and GenBank databases, and amino acid translation was done with the invertebrate mitochondrial criterion in MEGA 7.0 (Kumar et al. 2016) to detect possible Numts (nuclear copies of mtDNA fragments) (Song et al. 2008; Bertheau et al. 2011). A search for non-synonymous mutations, in-frame stop codons and indels was also carried out to detect possible cryptic Numts. The Kimura two-parameter (Kimura 1980) distances between taxa were calculated in MEGA 7.0.

All sequences were included in the phylogenetic reconstructions without pruning identical haplotypes to test the phylogenetic integrity of the species as identified using morphological characters (Ivshin et al. 2018; Cheng et al. 2017; Nässig et al. 2010). The phylogeny was reconstructed using a Bayesian Inference (BI) criterion as implemented in PhyloSuite 1.2.2 (Zhang et al. 2020). We used a reversible-jump Markov Chain Monte Carlo (rj-MCMC) method to allow sampling across the entire substitution rate model space (Huelsenbeck et al. 2004). BI analyses consisted of two independent runs, each with eight rj-MCMC running for five million generations (sampled every $1000^{\text {th }}$ generation) to calculate the clade posterior probabilities (PP). The marginal likelihood estimate was performed with stepping-stone sampling (Xie et al. 2011), as implemented in MrBayes with 100 steps, each with 10 million generations, and a diagnostic frequency of 1000. Finally, Monophylizer (http://monophylizer.naturalis.nl/) (Mutanen et al. 2016) was applied to the resultant BI tree to test the monophyly of each identified taxon.

\section{Results}

\section{Molecular Phylogenetics}

Bayesian phylogenetic analyses converged well, as indicated by an average standard deviation of split frequencies close to $0(0.004874)$, potential scale reduction factors equal to 1 (maximum $=1.005)$, and an effective sample size >> 200 for all parameters. The phylogeny recovered three major clades, each with a maximal PP value (Figure 2).

In the first of these clades, comprising $R$. davidi, $R$. davidi 'namvui', $R$. kitchingi and $R$. xinyuae sp. nov., $R$. kitchingi and $R$. xinyuae sp. nov. are sister to each other, forming a monophyletic subgroup, and $R$. davidi and $R$. davidi 'namvui' together forming another. Sister to these four taxa is a clade comprising $R$. schnitzleri from northern Thailand and $R$. hainanensis from Hainan, with $R$. haxairei from central Vietnam being sister to all other species of this genus (Figure 2).

\section{Molecular species delimitation}

The Kimura two-parameter (K2P) distances among all taxa ranged from $0.77-6.16 \%$, with that between $R$. davidi 'namvui' and $R$. davidi being the smallest $(0.77 \%)$, and that between $R$. kitchingi and $R$. schnitzleri being the greatest (6.61\%) (Table 2). The distance between the new species and $R$. kitchingi is $2.16 \%$. The distances between the new species and other known Rhodambulyx species are all above this value.

TABLE 2. Kimura two-parameter (K2P) distances (in percentages) between all taxa of genus Rhodambulyx calculated from the DNA barcode sequences (COI), with species identified as in the Bayesian phylogenetic tree in Figure 2.

\begin{tabular}{lccccccc}
\hline & $\mathbf{1}$ & $\mathbf{2}$ & $\mathbf{3}$ & $\mathbf{4}$ & $\mathbf{5}$ & $\mathbf{6}$ & $\mathbf{7}$ \\
\hline 1. Rhodambulyx xinyuae sp. nov. & & & & & & & \\
2. Rhodambulyx kitchingi & 2.16 & & & & & & \\
3. Rhodambulyx davidi ' namvui' & 2.56 & 2.88 & & & & & \\
4. Rhodambulyx davidi & 3.04 & 3.04 & 0.77 & & & & \\
5. Rhodambulyx hainanensis & 4.83 & 5.16 & 4.75 & 4.92 & & & \\
6. Rhodambulyx haxairei & 4.99 & 5.23 & 5.12 & 5.29 & 3.13 & & \\
7. Rhodambulyx schnitzleri & 5.15 & 6.16 & 5.58 & 5.42 & 2.97 & 4.85 & \\
\hline
\end{tabular}


The Monophylizer analysis supported all morphologically analysed species of two or more samples as monophyletic on the BI tree (Table 3). The results showed that the samples of the new species also formed a monophyletic group.

Overall, given the aforementioned molecular evidence, we propose that the Rhodambulyx from Chongqing is a new species and describe it below.

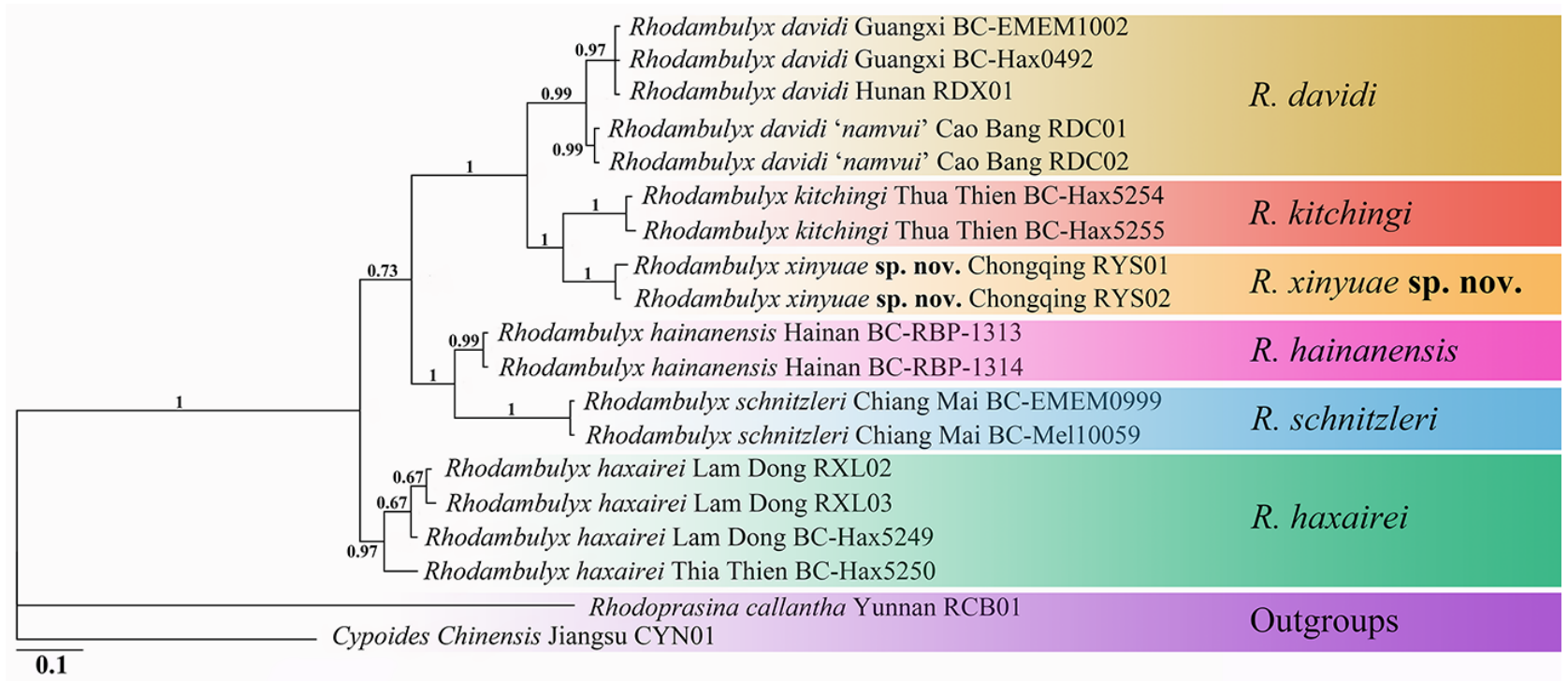

FIGURE 2. Bayesian inference phylogenetic tree of Rhodambulyx based on the DNA barcode sequences (COI) and rooted on Rhodoprasina callantha and Cypoides chinensis as outgroups. Values at the nodes indicate posterior probabilities.

TABLE 3. Monophylizer assessment of Rhodambulyx species used in this study.

\begin{tabular}{lll}
\hline Taxon & Assessment & Tanglees \\
\hline R. kitchingi & monophyletic & - \\
R. xinyuae sp. nov. & monophyletic & - \\
R. davidi & monophyletic & - \\
R. davidi 'namvui' & monophyletic & - \\
R. hainanensis & monophyletic & - \\
R. schnitzleri & monophyletic & - \\
R. haxairei & monophyletic & \\
\hline
\end{tabular}

\section{Rhodambulyx xinyuae Xu, Melichar \& He sp. nov. 芯语红鹰天蛾}

HOLOTYPE: đ̊, Dawopu (1,200-1,300 m), Simianshan, Jiangjin District, S. W. Chongqing, China, 2019-III-3, C. Zhang leg. [KIZ 0136260]. PARATYPES: $2 \hat{\jmath} \hat{o}$, the same data as the holotype, C. Zhang leg. [ZBX][GenBank accession no.: MZ606150 and MZ606151]; to be transferred to KIZ at a later date]; $1 \hat{\delta}$, the same collecting data, [KIZ 0136261]; 1§̂, Tudiyan (1,100 m), Simianshan, Jiangjin District, S. W. Chongqing, China, 2021-II-22, C. Zhang leg. [KIZ 0136262].

\section{Description:}

Male (Figure 3 A-D). Forewing length 39-42 mm, ground colour brownish,with some individuals more reddish. Body brownish. Antenna about one-third of forewing length, beige with brownish pectinations. Forewing upperside: Ground colour brownish-beige, with three transverse darker brown bands overlain by a faintly silvery sheen. Discal spot creamy yellow. Subapical patch paler, running from costa to vein $\mathrm{M}_{3}$, crossed by the postdiscal band, immediately adjacent to which is a brownish apical patch. Terminal band inwardly wavy with silvery sheen. Forewing underside: Light buff-brown peppered with darker scales, basal half covered with reddish hair forming a patch. Discal band darker, running from costa into the basal reddish patch. Submarginal line rather thin, Y-shaped running from apex and costa to cell $\mathrm{CuA}_{1}$, bifurcating in cell $\mathrm{M}_{1}$. Hindwing upperside: Ground colour brownish-red. 
Darker postmedial line rather obscure. Narrow black outer margin fades inwardly. Hindwing underside: Postmedial and submarginal bands brownish-red, distinctly delineated. Cilia creamy yellow.

Female. Unknown.

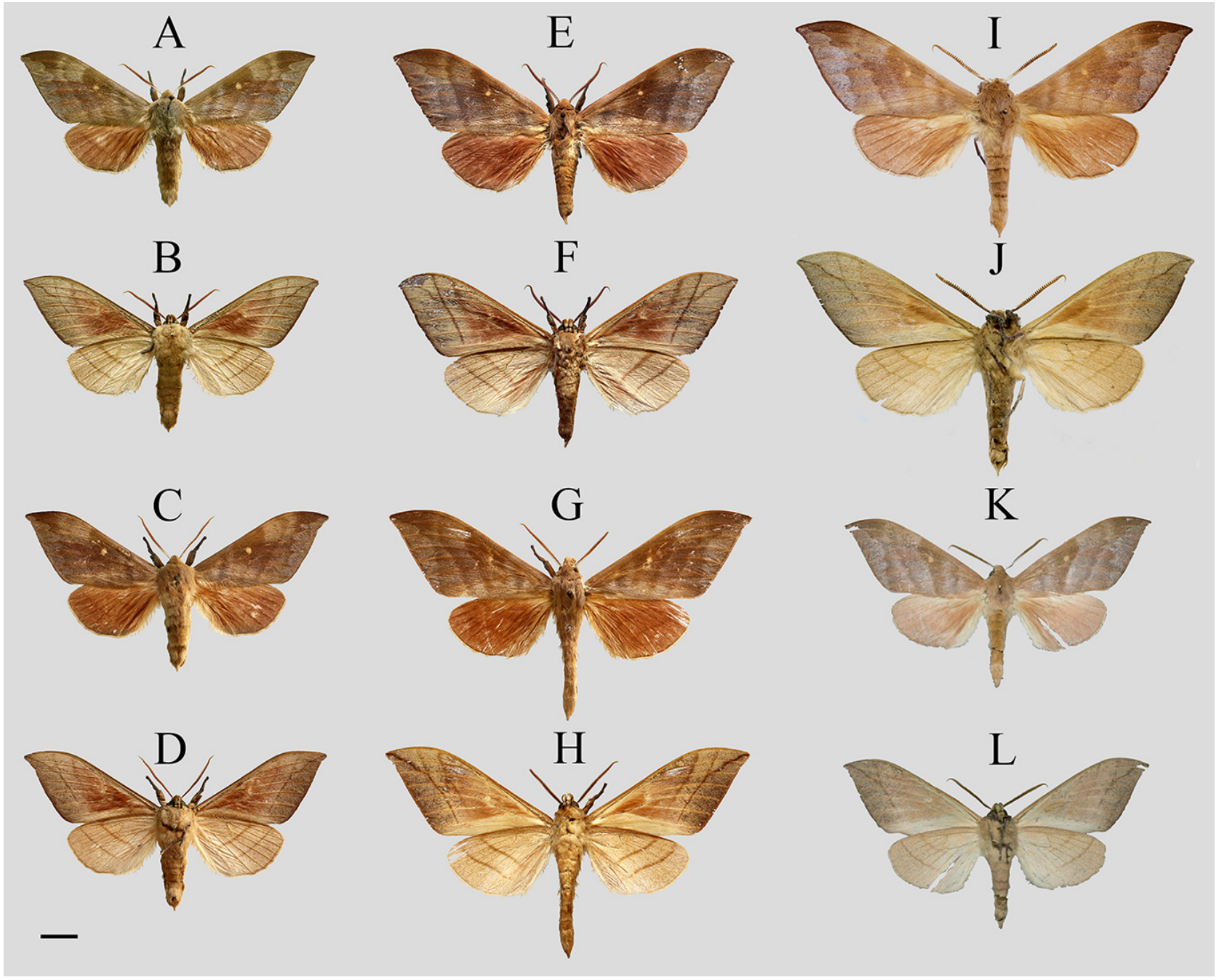

FIGURE 3. Rhodambulyx xinyuae Xu, Melichar \& He sp. nov. (A-D) and three similar taxa, R. kitchingi Brechlin, 2015 (E-H)

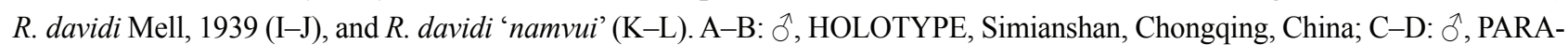
TYPE, same locality as holotype; E-F: $\widehat{O}$, Da Nang, Lam Dong, Vietnam; G-H: $\widehat{\partial}$, Bach Ma, Thua Thien Hue, Vietnam; I-J: $\widehat{O}$, Dayao shan, Guangxi China; K-L: đ, HOLOTYPE, Phia Den, Cao Bang, Vietnam, C Ulf Eitschberger. Scale bar $=10 \mathrm{~mm}$.

Male genitalia. In total, five genitalia were dissected. Overall, heavily sclerotized. Tegumen and vinculum broad, the latter with a very short saccus (Figure 4A and B); uncus broadest at base, elongate, gradually narrowing towards a slightly bifurcate tip; apical third ventrally with a median ridge that bifurcates into two apical ridges (Figure 7A), and which is individually variable in shape (see Figure 7D). Valve broad in basal half, nearly rectangular, elongate and more membranous in the distal half, covered with dense setae, harpe triangular, broad at base and gradually narrowed, then abruptly upturned into hooked tip (Figure 7B and E). Juxta thin, rising from base of valve. Phallus of moderate length, straight; basal half narrower, distal half approximately of equal width; tip pointed with smooth cornuti (Figure 7C and F).

Female genitalia. Unknown.

Voltinism: Univoltine, adults appearing from mid-February to early March. In the same area, no adults have been found in other months, and no other species of the same genus have been found.

Distribution: Currently known only from the Simianshan, S. W. Chongqing.

Derivatio nominis: The species is dedicated to Ms Xin-Yu Zhang (Chongqing, China), wife of Chao Zhang. Zhang decided to express his love for his wife and her unselfish companionship and support over the years.

Biology: The adults appear in February and March, flying in Subtropical Evergreen Broad-leaved Forest with foggy weather. Larval hostplants unknown. 


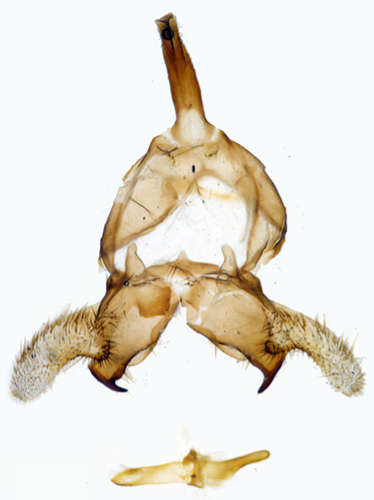

A
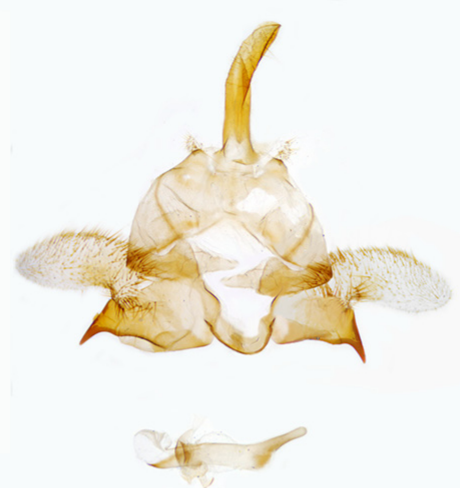

B
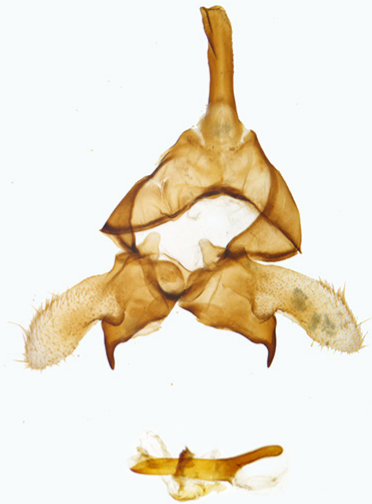

C

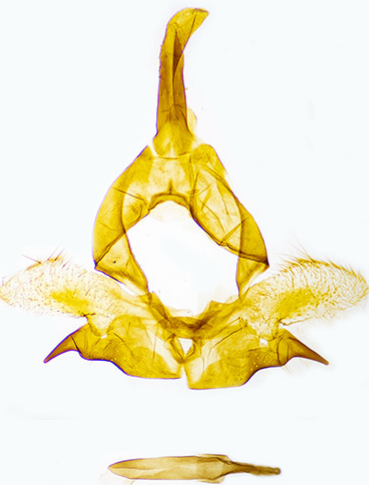

D

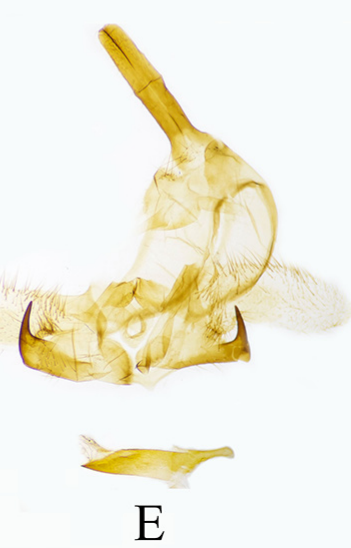

FIGURE 4. Male genitalia of Rhodambulyx xinyuae Xu, Melichar \& He sp. nov., Simianshan, Chongqing, China (A-B); $R$. kitchingi Brechlin, 2015, Thua Thien Hue, Vietnam (C-D); and R. davidi Mell, 1939, Dayao shan, Guangxi, China (E).

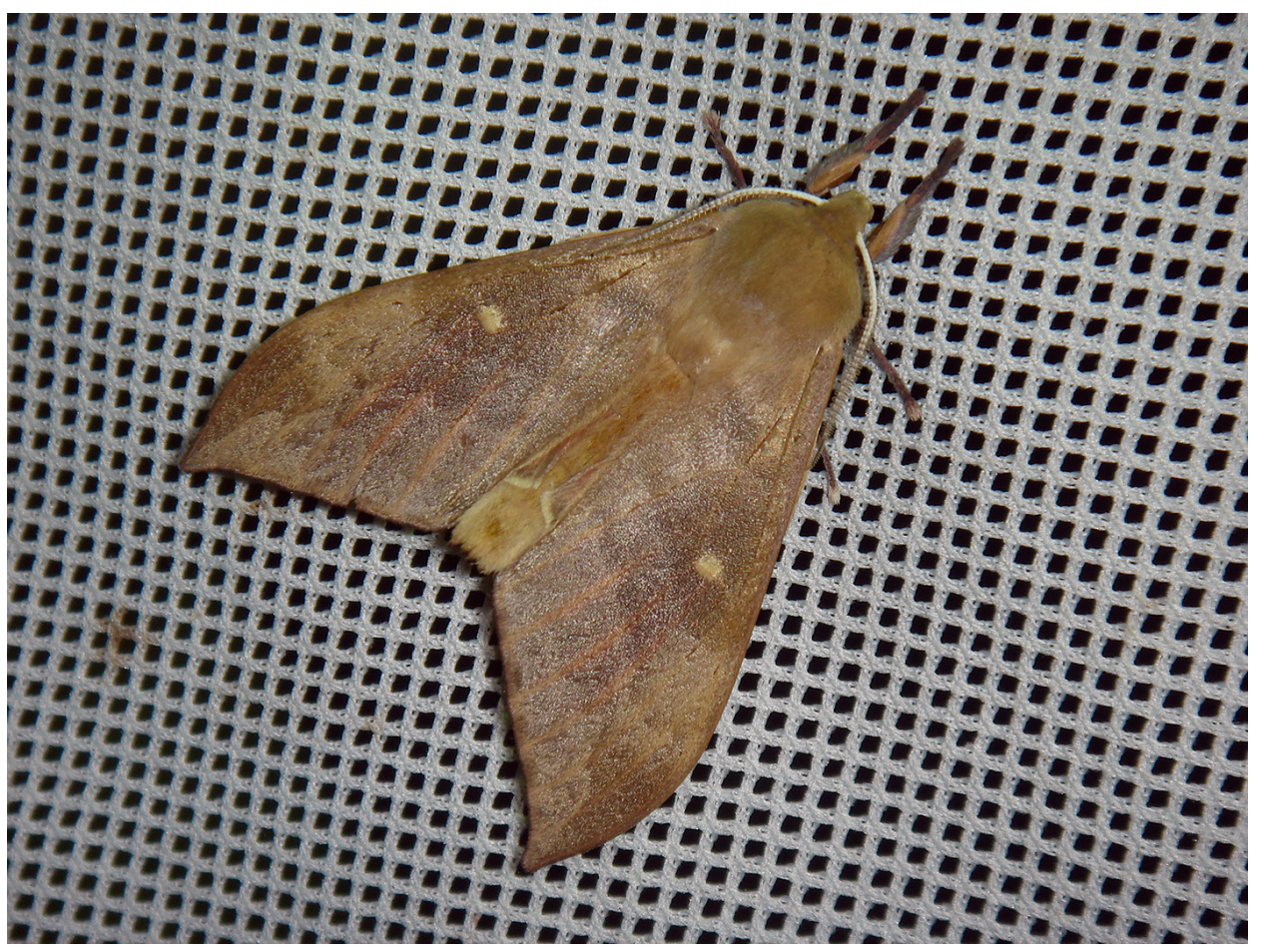

FIGURE 5. Photo of live Rhodambulyx xinyuae Xu, Melichar \& He sp. nov. Taken in Tudiyan, Simianshan, Jiangjin District, S. W. Chongqing, China, 2021-II-22, by Chao Zhang. 


\section{Morphological comparison with similar species}

Since $R$. xinyuae sp. nov. is readily distinguishable from R. hainanensis, R. haxairei, and R. schnitzleri (Figure 6), the present study hereafter only compares it with the two most similar species, namely $R$. davidi and $R$. kitchingi.

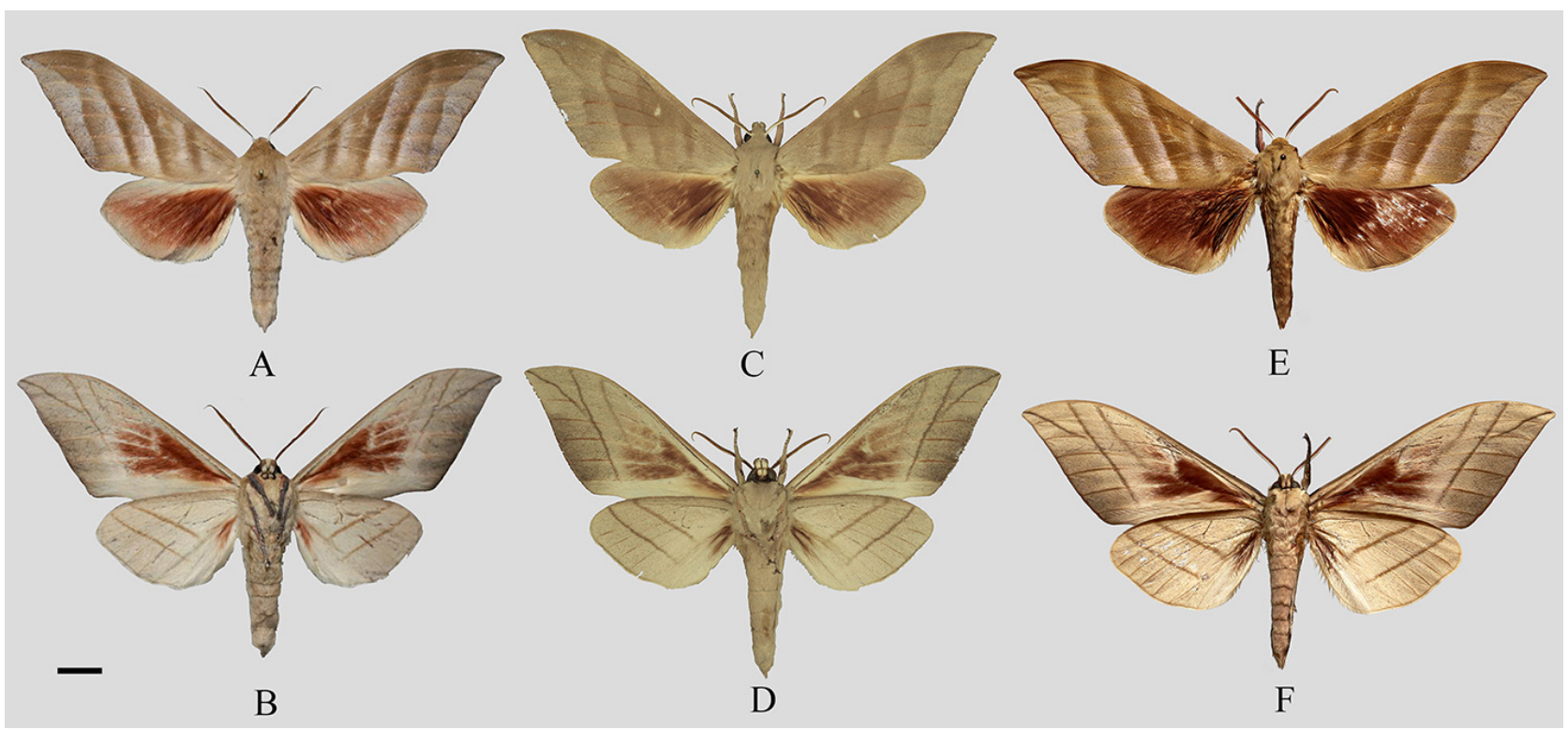

FIGURE 6. Photos of Rhodambulyx schnitzleri Cadiou, 1990 (A-B), R. hainanensis Brechlin, 2001 (C-D), and R. haxairei Melichar, Řezáč \& Horecký, 2014 (E-F). A-B: §̂, Doi Pha Hom Pok, Chiang Mai, Thailand, C Ulf Eitschberger; C-D: §̂, HOLOTYPE, Wuzhi Shan, Hainan, China, (C) The Trustees of the Natural History Museum, London. https://sphingidae.myspecies. info/taxonomy/term/2493; E-F: đ̃, Da Nang, Lam Dong, Vietnam.

\section{Rhodambulyx davidi Mell, 1939}

Male (Figure $3 \mathrm{I}-\mathrm{J}$ ). Forewing length $42-54 \mathrm{~mm}$, ochre. Body brownish. Antenna about one-third of forewing length, beige with brownish pectinations. Forewing upperside: Ground colour reddish-beige with three transverse light brown bands overlain by a clear silvery sheen. Discal spot creamy yellow. Postdiscal band wavy, running from costa to inner margin. Terminal band inwardly wavy with strongly silvery sheen. Brownish apical patch distinct. Forewing underside: Light buff-brown peppered with darker scales, basal half covered with faintly brownish-beige hair forming a patch. Discal band obscure, running from costa into the basal brownish-beige patch. Submarginal line thin, Y-shaped running from apex and costa, gradually disappearing to cell $\mathrm{CuA}_{1}$, bifurcating in cell $\mathrm{M}_{1}$. Faintly black terminal band slightly disappeared to basal. Hindwing upperside: Ochre-beige with narrow black outer margin. Darker postdiscal line rather disappeared. Hindwing underside: Postdiscal and submarginal bands ochre, slightly indistinct. Cilia reddish beige.

Male genitalia. In total, seven genitalia were dissected. Overall sclerotized. Tegumen and vinculum broad, the latter with a short saccus (Figure 3C and D); uncus broad at base, elongate, triangular shaped with blunt tip (Figure $7 \mathrm{M})$. Valve broad in basal half, nearly oval, elongate and more membranous in the distal half, covered with dense setae, harpe triangular, broad at base and gradually narrowed, then abruptly upturned into hooked tip (Figure 7N). Juxta thin, rising from base to valve. Phallus straight, basal half and distal half approximately of equal width; distal half gradually narrowed with teardrop-shaped tip (Figure 70).

\section{Rhodambulyx kitchingi Brechlin, 2015}

Male (Figure $3 \mathrm{E}-\mathrm{H}$ ). Forewing length $43-49 \mathrm{~mm}$, brownish ochre. Body brownish. Antenna about one-third of forewing length, beige with brownish pectinations. Forewing upperside: Ground colour reddish-beige, with three distinctly transverse darker brown bands overlain by a faintly silvery sheen. Discal spot creamy yellow. Postdiscal band straight, running from costa to inner margin. Terminal band inwardly wavy with silvery sheen. Apical patch 
brownish with obscure boundary inwardly. Forewing underside: Buff-brown peppered with darker scales, basal half covered with reddish hair forming a patch. Discal band darker and distinct, running from costa into the basal reddish patch. Submarginal line distinct, Y-shaped running from apex and costa to cell $\mathrm{CuA}$, bifurcating in cell $\mathrm{M}_{1}$. Hindwing upperside: Ground colour brownish-red. Darker postdiscal line obscure, with narrow black outer margin. Hindwing underside: Postdiscal and submarginal bands brownish-red, distinctly delineated. Cilia creamy yellow.

Male genitalia. In total, seven genitalia were dissected. Overall heavily sclerotized. Tegumen and vinculum broad, the latter with a short saccus (Figure 3C and D); uncus broadest at base, elongate towards a bifurcate tip (Figure 7G); apical third ventrally with a median ridge that bifurcate into two apical ridges, and which is individually variable in shape (see Figure $7 \mathrm{~J}$ ). Valve broad in basal half, nearly rhombic, elongate and more membranous in the distal half, covered with dense setae, harpe triangular, broad at base and gradually narrowed, then abruptly downward into hooked tip (Figure 7H and K). Phallus of moderate length, straight; basal half narrower; distal half approximately of equal width; tip elongated and pointed with smooth cornuti (Figure 7I and L ).

Diagnostic characters: The two known species $(R$. davidi and $R$. kitchingi) can be distinguished by the following characters: (1) R. kitchingi is more reddish than $R$. davidi in external appearance. (2) The brownish apical patch of forewing upperside in $R$. davidi more distinct than $R$. kitchingi. (3) The postdiscal band of forewing in $R$. kitchingi is straighter than that of $R$. davidi. (4) The discal band on the forewing underside in $R$. kitchingi is more distinct than that of $R$. davidi. (5) The postdiscal and submarginal bands in hindwing underside are more distinct in $R$. kitchingi (Figure 3). Genitally: (1) The pointed triangular tip in the uncus of $R$. davidi is far less obvious, appearing almost rounded. (2) The harpe is thinner and sharper in R. davidi than in R. kitchingi (Figure 4 and Figure 7).

The new species resembles $R$. kitchingi from central Vietnam but can be distinguished from the following characteristics: (1) Its smaller size on average, (2) the brownish apical patch of forewing upperside more distinct than $R$. kitchingi, (3) the duller silvery sheen on the forewing upperside in new species. (4) The discal band on the forewing underside in the new species is not as distinct as that in R. kitchingi. (5) The narrow black margin fades inwardly in hindwing upperside of new species, but this feature is not obvious in R. kitchingi (Figure 3). In male genitalia, the diagnostic differences are: (1) the uncus of the new species is not gradually tapered distally as it is in $R$. kitchingi (2) the dorsal margin of harpe is smoother rather than wavy in R. kitchingi (3) the phallus is shorter with a shorter tip (Figure 4 and Figure7).

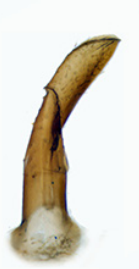

A

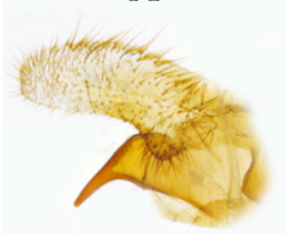

B

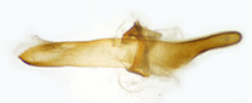

C

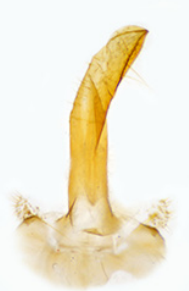

D

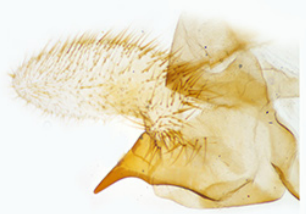

E

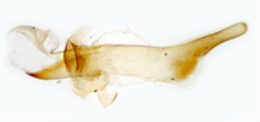

F

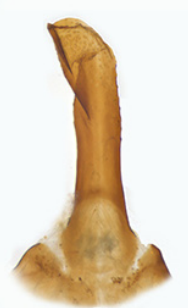

G

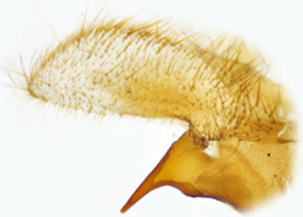

$\mathrm{H}$

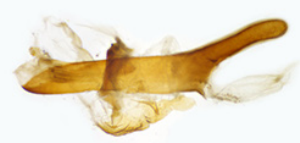

I

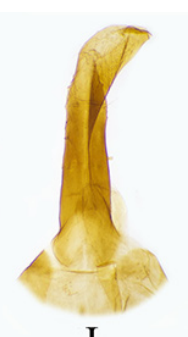

J

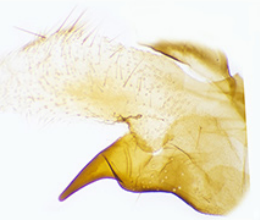

K

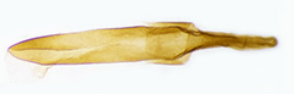

L

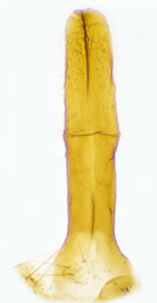

M

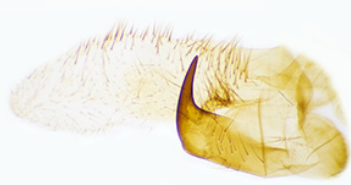

N

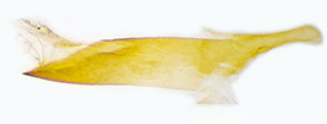

O

FIGURE 7. Enlarged uncus, valve, and phallus of male genitalia of Rhodambulyx xinyuae Xu, Melichar \& He sp. nov., Simianshan, Chongqing, China (A-F); R. kitchingi Brechlin, 2015, Thua Thien Hue, Vietnam (G-L); and R. davidi Mell, 1939, Dayao Shan, Guangxi, China (M-O). A, D, G, J, and M: ventral-lateral view of uncus; B, E, H, K, and N: posterior view of valve and harpe; C, F, I, L, and O: lateral view of phallus.

Rhodambulyx xinyuae sp. nov. is also similar to $R$. davidi. However: (1) The delimited subquadrate creamy yellow patch on the forewing in the new species is more evident than that in $R$. davidi. (2) The postdiscal band of fore- 
wing upperside in the new species, straighter than that in $R$. davidi. (3) The postmedial and submarginal bands on hindwing underside of the new species are more distinct than those of $R$. davidi. (4) The narrow black outer margin of the hindwing fades inwardly in the new species, which is not obvious in $R$. davidi (Figure 3). In male genitalia, the diagnostic differences are: (1) The pointed triangular tip in the uncus of $R$. davidi is far less obvious, appearing almost rounded. (2) The harpe is sharper in $R$. davidi than in $R$. xinyuae sp. nov. (Figure 4 and Figure 7).

\section{Discussion}

Our findings showed that Rhodambulyx xinyuae sp. nov. from Simianshan is a species different from others in the genus Rhodambulyx. The molecular data showed the genetic distinctness and integrity of the new species (Figure 2; Table 3). Although the K2P genetic distance (2.16\%) is smaller than that between many Smerinthini at the species level (which often exceeds 4\%; Řezáč, 2018), we consider that the evidence from the morphological analyses of the genital structures and wing patterns and the monophyly shown in the phylogenetic analysis is sufficient that Rhodambulyx xinyuae sp. nov. can be treated as a good species (Meyer et al. 2005; Řezáč 2018). The paler subapical costal patch on the forewing upperside serves as a good diagnostic feature of the new species.

The K2P genetic distance between $R$. xinyuae sp. nov. and $R$. kitchingi is small for two species in the genus Rhodambulyx, which may imply a possibly recent divergence of the two taxa. Currently, $R$. xinyuae sp. nov. is only known from its type locality, and its full geographic range is still unclear. Although the distributions of all Rhodambulyx species are geographically well separated, with $R$. davidi occurring between $R$. xinyuae sp. nov. and $R$. kitchingi (Figure 1), we cannot rule out the possibility of at least partial overlapping distributions of the three species. Future surveys will be necessary to confirm or refute this, as well as to determine the full range of $R$. xinyuae sp. nov. However, similar biogeographical patterns have been reported in Graphium subgenus Pazala Moore, 1888, e.g., Graphium (Pazala) confucius Cotton \& Hu, 2018, G. (P.) daiyuanae Hu \& Cotton, 2018, and G. (P.) wenlingae $\mathrm{Hu}$, Cotton \& Monastyrskii, 2019 in Southwest China and Vietnam (Hu et al. 2018; Hu et al. 2019), as well as in Saturniidae moths, where Actias chapae Mell, 1950 has two subspecies in this area, with the nominotypical subspecies occupying central, southwest and south China, as well as North Vietnam, with another subspecies found in south Vietnam (Wu \& Naumann 2006; Sochivko \& Ivshin 2008; Zhang 2013). A similar pattern is seen in Rhodoprasina callantha Jordan, 1929, which has two subspecies in southwest China and a third in Central Vietnam (Brechlin 2015).

We would note that although $R$. davidi 'namvui' forms a separate branch on the Bayesian tree from $R$. davidi (Figure 2; Table 3), the K2P genetic distance is relatively low (Table 2). In the male genitalia, the tip of phallus in $R$. davidi 'namvui' is shorter than that of $R$. kitchingi (Figure 8J, N, and $\mathrm{R}$ ), the apex of uncus in $R$. kitchingi has a distinct fold that is absent in $R$. davidi 'namvui' (Figure 8K, O, and $\mathrm{S}$ ), the valve of $R$. davidi 'namvui' more elliptical, unlike the downward beak-shaped in R. kitchingi (Figure 8L, P, and T). Although the apex of uncus in R. davidi 'namvui' is slightly different from that of $R$. davidi in its gradually tapered shaft and a blunt tip, it is still too soon to conclude whether such differences are merely individual variation between populations due to the limited number of specimens examined. Overall, all these aforementioned genital characteristics of $R$. davidi 'namvui' are closer to $R$. davidi rather than to $R$. kitchingi. Moreover, the external morphological appearance of $R$. davidi 'namvui' is similar to $R$. davidi, but different from R. kitchingi (Figure 3). Originally, $R$. davidi 'namvui' was described as a distinct species (Eitschberger \& Nguyen 2017) but was then later synonymized with $R$. kitchingi (Eitschberger 2018). Our analysis does not support $R$. davidi 'namvui' being a junior synonym of $R$. kitchingi but rather shows it has a closer relationship with $R$. davidi. Considering the spatial distribution pattern of the three taxa, we believe that $R$. namvui is a southern population of $R$. davidi. However, whether it is a subspecies of $R$. davidi or just a junior synonym of that species requires further investigation with additional material and DNA data. For now, we provisionally treat $R$. namvui syn. nov. as a junior synonym of $R$. davidi.

Rhodambulyx xinyuae sp. nov. is the northernmost species of the genus, relatively isolated from the other species, which occur further south in southern China and northern Indochina. The presence of a species of Rhodambulyx in this region of southern Chongqing may be attributable to the Simianshan being a transition zone between the Yunnan-Guizhou Plateau and the Sichuan Basin. By reason of a favorable climate and sufficient rainfall, the entire zone is luxuriant subtropical evergreen broad-leaved forests ( $\mathrm{Li} \& \mathrm{Hou}, 2004$ ) suitable for these tropical hawkmoths. The distribution of Rhodambulyx in Chongqing, Guizhou, and Sichuan certainly needs further investigation. 


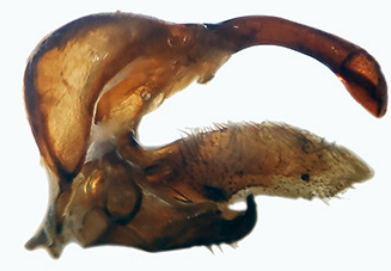

A

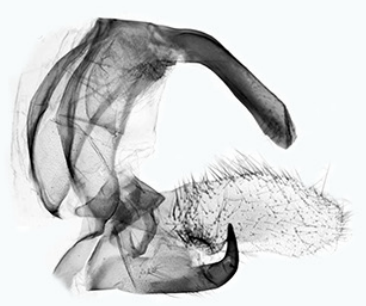

E

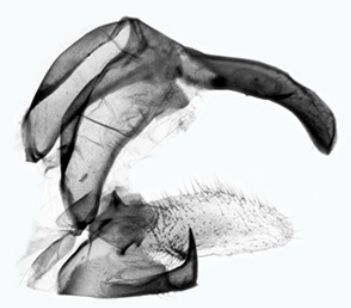

I

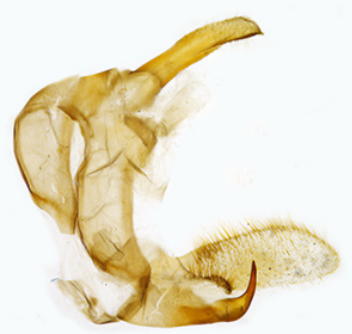

M

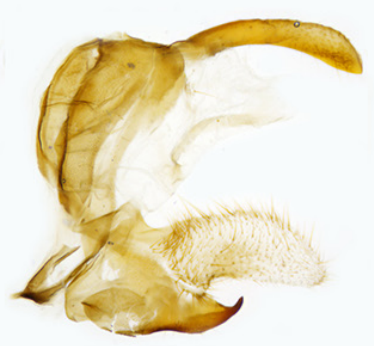

Q

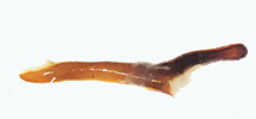

B

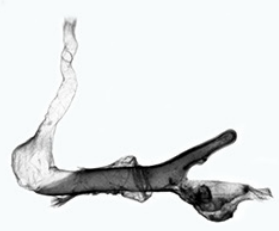

F

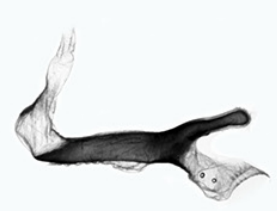

J

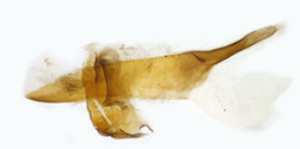

$\mathrm{N}$

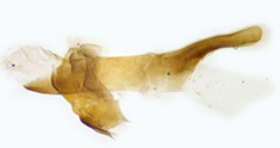

$\mathrm{R}$

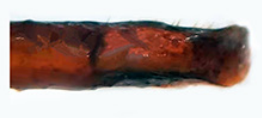

C

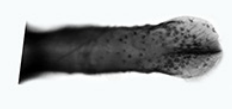

G

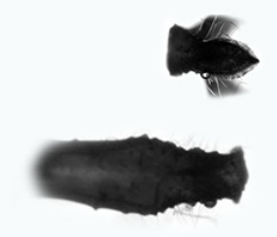

K

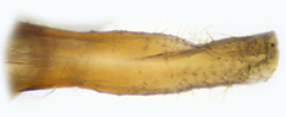

$\mathrm{O}$

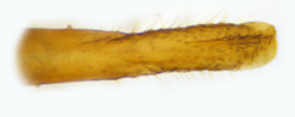

S

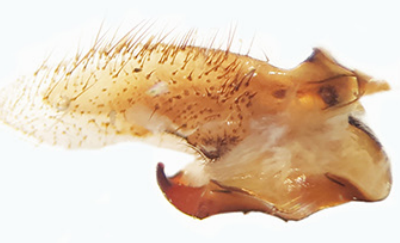

D

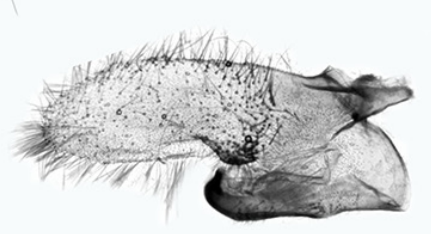

$\mathrm{H}$

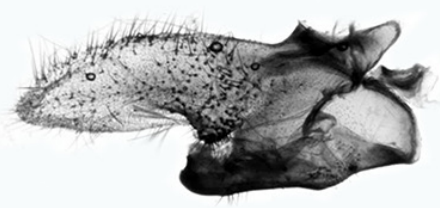

$\mathrm{L}$

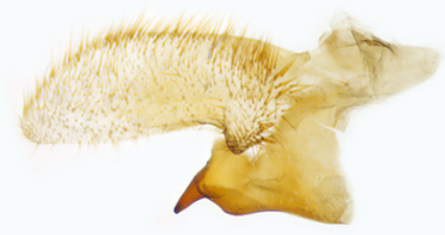

$\mathrm{P}$

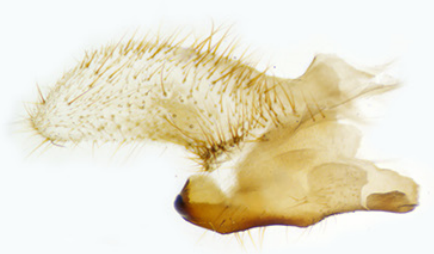

$\mathrm{T}$

FIGURE 8. Male genitalia of Rhodambulyx davidi Mell, 1939, from Shunhuang Shan, Hunan, China (A-D, (C) Zhuo-Heng Jiang) and Wuyi Shan, Fujian, China (E-H, C Ulf Eitschberger); R. davidi 'namvui', Phia Den, Cao Bang, Vietnam (I-L, (C) Ulf Eitschberger), R. kitchingi Brechlin, 2015, Thua Thien Hue, Vietnam (M-T). A, E, I, M, and Q: lateral view of the whole genitalia with left valve removed; ,B, F, J, N, and R: lateral view of phallus; C, G, O, and S: dorsal view of uncus; K: dorsal view of uncus and enlarged apex of uncus; D, H, L, P, and T: lateral view of left valve. 


\section{Acknowledgements}

The authors would like to thank Dr. Ian. J. Kitching (Natural History Museum, London, UK) for his valuable comments, Mr. Jean Haxaire (Muséum national d'Histoire naturelle, Paris, France), Dr. Ulf Eitschberger (Entomologischen Museum, Marktleuten, Germany) and Mr. Zhuo-Heng Jiang (Westlake University, Hangzhou, China) for sample collection and information; Prof. Chuan-Hui Yi and Prof. Qiu-Ju He (Southwest Forestry University, Kunming, China) for allowing specimen examination; and Prof. Qin Qiao (Yunnan University, Kunming, China) and Tian-Tian Yu (South China Agricultural University, Guangzhou, China) for their valuable opinions and assistance. We also thank Si-Yao Huang (Zhuhai, China) and Hui-Hong Zhang (Kunming, China) for giving constructive suggestions to this study.

\section{References}

Bertheau, C., Schuler, H., Krumböck, S., Arthofer, W. \& Stauffer, C. (2011) Hit or miss in phylogenetic analyses: The case of the cryptic NUMTs. Molecular Ecology Resources, 11, 1056-1059. https://doi.org/10.1111/j.1755-0998.2011.03050.x

Brechlin, R. (2001) Rhodambulyx hainanensis, eine neue Schwärmerart aus China (Lepidoptera: Sphingidae). Nachrichten des entomologischen Vereins Apollo, Neue Folge, 22, 145-147.

Brechlin, R. (2015) Rhodambulyx kitchingi n. sp., eine neue Sphingide aus Vietnam (Lepidoptera: Sphingidae). Entomo-Satsphingia, 8, 5-7.

Brechlin, R. (2015) Zwei neue Unterarten von Rhodoprasina callantha Jordan, 1926 (Lepidoptera, Sphingidae). Entomo-Satsphingia, 8, 26-30.

Cadiou, J.-M. (1990) A new sphingid from Thailand: Rhodambulyx schnitzleri (Lepidoptera Sphingidae). Lambillionea, 90 (2), $42-48$.

Chen, J. \& Ou, X.H. (2008) Two new record species of Sphingidae (Lepidoptera) from China. Entomotaxonomia, 30 (1), 39-40.

Cheng, R., Xue, D.Y., Galsworthy, A., \& Han, H.X. (2017) Complete mitochondrial genomes throw light on budding speciation in three Biston species (Lepidoptera, Geometridae). Zoologica Scripta, 46, 73-84. https://doi.org/10.1111/zsc. 12184

Eitschberger, U. \& Nguyen, H.B. (2017) Rhodambulyx namvui spec. nov., eine neue Schwärmerart aus Vietnam (Lepidoptera, Sphingidae). Neue Entomologische Nachrichten, 74, 172-192.

Eitschberger, U. (2018) Die Taxa des Genus Rhodambulyx Mell, 1939 mit neuer Synonymie (Lepidoptera, Sphingidae). Neue Entomologische Nachrichten, 75, 94-95.

Hall, T.A. (1999) BioEdit: A user-friendly biological sequence alignment editor and analysis program for Windows 95/98/NT. Nucleic Acids Symposium Series, 41, 95-98.

Huelsenbeck, J.P., Larget, B. \& Alfaro, M.E. (2004) Bayesian phylogenetic model selection using reversible jump Markov Chain Monte Carlo. Molecular Biology and Evolution, 21, 1123-1133. https://doi.org/10.1093/molbev/msh123

Hu, S.J., Cotton, A.M., Condamine, F.L., Duan, K., Wang, R.J., Hsu, Y.F., Zhang, X. \& Cao, J. (2018) Revision of Pazala Moore, 1888: the Graphium (Pazala) mandarinus (Oberthür, 1879) group, with treatments of known taxa and descriptions of new species and new subspecies (Lepidoptera: Papilionidae). Zootaxa, 4441 (3), 401-446. https://doi.org/10.11646/zootaxa.4441.3.1

Hu, S.J., Condamine, F.L., Monastyrskii, A.L. \& Cotton, A.M. (2019) A new species of the Graphium (Pazala) mandarinus Group from Central Vietnam (Lepidoptera: Papilionidae). Zootaxa, 4554 (10, 286-300.

https://doi.org/10.11646/zootaxa.4554.1.10

Ivshin, N., Krutov, V. \& Romanov, D. (2018) Three new taxa of the genus Cechetra Zolotuhin \& Ryabov, 2012 (Lepidoptera, Sphingidae) from South-East Asia with notes on other species of the genus. Zootaxa, 4450 (1), 1-25. https://doi.org/10.11646/zootaxa.4450.1.1

Kimura, M. (1980) A simple method for estimating evolutionary rates of base substitutions through comparative studies of nucleotide sequences. Journal of Molecular Evolution, 16, 111-120. https://doi.org/10.1007/BF01731581

Kitching, I.J. \& Cadiou, J.-M. (2000) Hawkmoths of the World: an annotated and illustrated revisionary checklist (Lepidoptera: Sphingidae). Natural History Museum, London and Cornell University Press, Ithaca, New York, 226 pp., 8 pls.

Kumar, S., Stecher, G. \& Tamura, K. (2016) Molecular evolutionary genetics analysis version 7.0 for bigger datasets. Molecular Biology \& Evolution, 33, 1870-1874. https://doi.org/10.1093/molbev/msw054

Melichar, T., Řezáč, M. \& Horecký, Č. (2014) A new species of the genus Rhodambulyx Mell, 1939 (Lepidoptera, Sphingidae) from Vietnam. The European Entomologist, 6, 161-165. 
Mell, R. (1939) Beiträge zur Fauna sinica. XVIII. Noch unbeschriebene chinesische Lepidopteren (V). Deutsche Entomologische Zeitschrift, Berlin, 52, 135-152.

Mell, R. (1950) Aus der Biologie der chinesischen Actias Leach (Argema chapae sp. n., A. sinensis f. virescens f. n.). Entomologische Zeitschrift, 60, 6 \& 7, 41-45 \& 53-56.

Meyer, C.P. \& Paulay, G. (2005) DNA barcoding: error rates based on comprehensive sampling. PLoS Biology, 3 , e422. https://doi.org/10.1371/journal.pbio.0030422

Moore, F. (1888) Additional Species Family Papilionidae. In: Hewitson \& Moore (1879-1888), Description of New Indian Lepidopterous Insects from the Collection of the Late Mr. W.S. Atkinson, M.A., F.L.S., \& c., Director of the Public Instruction, Bengal. Rhopalocera. Part III. Asiatic Society of Bengal, Calcutta, pp. 283-285.

Wu Y. \& Naumann, S. (2006) The preimaginal instars of Actias chapae (Mell, 1950) (Lepidoptera: Saturniidae). Nachrichten des entomologischen Vereins Apollo, Neue Folge, 27, 1/2, 17-21.

Mutanen, M., Kivelä, S.M., Vos, R.A., Doorenweerd, C., Ratnasingham, S., Hausmann, A., Huemer, P., Dincă, V., van Nieukerken, E.J., Lopez-Vaamonde, C., Vila, R., Aarvik, L., Decaëns, T., Efetov, K.A., Hebert, P.D.N., Johnsen, A., Karsholt O., Pentinsaari, M., Rougerie, R., Segerer, A., Tarmann, G., Zahiri, R. \& Godfray, H.C.J. (2016) Species-level para- and polyphyly in DNA barcode gene trees: strong operational bias in European Lepidoptera. Systematic Biology, 65, 1024-1040. https://doi.org/10.1093/sysbio/syw044

Nässig, W.A., Naumann, S. \& Rougerie. (2010) Evidence for the existence of three species in the genus Archaeoattacus (Lepidoptera: Saturniidae). The Journal of Research on the Lepidoptera, 43, 37-47.

Řezáč, M. (2018) Notes on the taxonomy of the genus Rhodoprasina Rothschild \& Jordan, 1903 (Lepidoptera, Sphingidae) with the description of a new species. The European Entomologist, 10 (1), 185-206.

Song, H., Buhay, J.E., Whiting, M.F. \& Crandall, K.A. (2008) Many species in one: DNA barcoding overestimates the number of species when nuclear mitochondrial pseudogenes are coamplified. PNAS, 105, 13486-13491. https://doi.org/10.1073/pnas.0803076105

Thompson, J.D., Higgins, D.G. \& Gibson, T.J. (1994) CLUSTAL W: Improving the sensitivity of progressive multiple sequence alignment through sequence weighting, position-specific gap penalties and weight matrix choice. Nucleic Acids Research, 22, 4673-4680. https://doi.org/10.1093/nar/22.22.4673

Xie, W.G., Lewis, P.O., Fan, Y., Kuo, L. \& Chen, M.H. (2011) Improving marginal likelihood estimation for Bayesian phylogenetic model selection. Systematic Biology, 60, 150-160. https://doi.org/10.1093/sysbio/syq085

Xu, Z.B., Wang, Y.Y., Condamine, F.L., Cotton, A.M. \& Hu, S.J. (2020) Are the Yellow and Red Marked Club-Tail Losaria coon the same species? Insects, 11, 392, 1-23. https://doi.org/10.3390/insects11060392

Zhang, D., Gao, F.L, Jakovlic, Zou, H., Li, W.X. \& Wang, G.T. (2020) PhyloSuite: An integrated and scalable desktop platform for streamlined molecular sequence data management and evolutionary phylogenetics studies. Molecular Ecology Resources, 20, 348-355. https://doi.org/10.1111/1755-0998.13096

Zhang, W.W. (2013) No Title [Introduction to cover photo Actias chapae]. Bulletin of Biology, 48, 4. https://doi.org/10.1016/j.materresbull.2012.10.030

\section{APPENDIX 1. Specimens examined in this study.}

\section{Rhodambulyx xinyuae Xu, Melichar \& He sp. nov. 芯语红鹰天蛾}

HOLOTYPE: đ̃, Dawopu (1,200-1,300 m), Simianshan, Jiangjin District, S. W. Chongqing, China, 2019-III-3, C. Zhang leg. [KIZ: 0130260]. PARATYPES: $2 \hat{\jmath} \widehat{\jmath}$, same data as holotype, C. Zhang leg. [ZBX]; $1 \hat{\jmath}$, same collecting data, [KIZ: 0130261]; 1ठ, Tudiyan (1,100 m), Simianshan, Jiangjin District, S. W. Chongqing, China, 2021-II-22, C. Zhang leg. [KIZ: 0130262].

\section{Rhodambulyx davidi Mell, 1939 大卫红鹰天蛾}

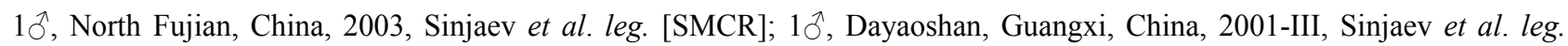

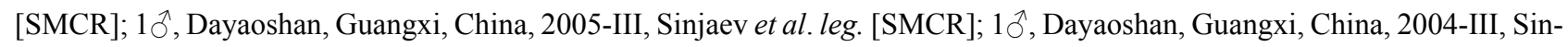
jaev et al. leg. [SMCR]; 1ठ̃, Shunhuangshan, Hunan, China, 2021-III, local catcher leg. [ZHJ]; $1 \hat{\jmath}$, Cenwanglaoshan, Guangxi, China, 2018-IX, local catcher leg. [ZHJ]; $1 \hat{\jmath}$, Wuyi Shan, Fujian, China, 2006-IV.-VII, local catcher leg. [EMM].

Rhodambulyx davidi 'namvui' (Eitschberger \& Nguyen, 2017)

$1 \hat{\jmath}$, HOLOTYPE, Phia Den, Cao Bang, Vietnam, 2017-II-22, Hoa Binh Nguyen leg. [EMM]; $1 \hat{\jmath}$, same locality as holotype, 2018-III, Hoa Binh Nguyen leg. [EMM]. 
Rhodambulyx kitchingi Brechlin, 2015 凯氏红鹰天蛾

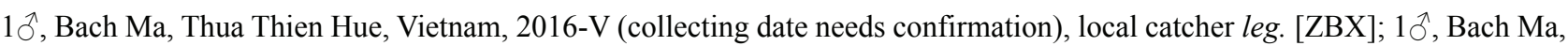
Thua Thien Hue, Vietnam, 2015-XIII (collecting date needs confirmation), local catcher leg. [ZBX]; 1ð̊, Bach Ma, Thua Thien Hue, Vietnam, 2016-III, local catcher leg. [ZBX]; 3ð, Da Nang, Lam Dong, Vietnam, 2020-I, local catcher leg. [ZBX]; 2へ, Kon Tum, Vietnam, 2017-II, local catcher leg. [ZBX], 1ð̊, Bach Ma, Thua Thien Hue, Vietnam, 2015, local catcher leg. [SMCR].

\section{Rhodambulyx schnitzleri Cadiou, 1990 施氏红鹰天蛾}

1ठð, Baoshan, Yunnan, China, 2002-IV, C. H. Yi leg. [SFU]; 1ðð, Mae Ai, Chiang Mai, Thailand, 2004-III-24, T. Ihle \& S. Loeffler leg. [SMCR]; 1ð, Doi Pha Hom Pok, Chiang Mai, Thailand, 2006-II, T. Ihle leg. [EMM]; 1ð̄, Doi Pha Hom Pok, Chiang Mai, Thailand, 2004-III, T. Ihle leg. [EMM].

\section{Rhodambulyx haxairei Melichar, Řezáč \& Horecký, 2014 哈氏红鹰天蛾}

1§̂, Da Nang, Lam Dong, Vietnam, 2020-I, local catcher leg. [ZBX]; 1\#, Da Nang, Lam Dong, Vietnam, 2019-III, local catcher leg. [ZBX]; 1ठ, Lam Dong, Vietnam, 2016-III, local catcher leg. [ZBX].

\section{Rhodambulyx hainanensis Brechlin, 2001 海南红鹰天蛾}

1̊̄, Wuzhi Shan, Hainan, China, 2000-III-1, Sinjaev leg. [BOLD]. 